\title{
Toll-Like Receptor Gene Expression in Nasal Polyp
}

\author{
Veysel Yurttas ${ }^{*}$, Tayfun Apuhan², Tugce Simsek¹, Zeynep Ocak³, Uzeyir Gok ${ }^{4}$ \\ ${ }^{1}$ Department of Otorhinolaryngology and Head and Neck Surgery, Abant İzzet Baysal University Faculty of \\ Medicine, Bolu, Turkey \\ ${ }^{2}$ Department of Otorhinolaryngology and Head and Neck Surgery, Intercontinental Hospital, Istanbul, Turkey \\ ${ }^{3}$ Department of Genetic, Abant Izzet Baysal University, Bolu, Turkey \\ ${ }^{4}$ Department of Otorhinolaryngology and Head and Neck Surgery, Medical Park Hospital, Elazığ, Turkey \\ Email: vyurttas@hotmail.com
}

Received 10 February 2016; accepted 15 March 2016; published 18 March 2016

Copyright (C) 2016 by authors and Scientific Research Publishing Inc.

This work is licensed under the Creative Commons Attribution International License (CC BY).

http://creativecommons.org/licenses/by/4.0/

(c) (i) Open Access

\begin{abstract}
Objective: To investigate the expression of Toll-like receptors (TLRs) and the correlation between TLR expression and mucosal changes in chronic sinusitis-related nasal polyposis. Methods: Patients with nasal polyps were enrolled in this study as the study group. The control group consisted of individuals undergoing surgery due to nasal obstruction caused by concha hypertrophy who were not diagnosed with chronic sinusitis-related nasal polyposis (NP). There were 30 patients in the study group (individuals with NP) and 20 patients in the control group. Sterile tissue samples were taken from the patients and were kept at $-80^{\circ} \mathrm{C}$. A piece of tissue sample was put into the eppendorf tube. Expression of TLR2 and TLR4 gene was investigated in the tissue samples. The samples were taken after the surgery; they were carried into the liquid nitrogen and were kept at $-80^{\circ} \mathrm{C}$ before study. Results: TLR2 and TLR4 expression was measured in both groups and then analyzed using Student's $t$-test. In the experimental group, the level of TLR2 expression was significantly higher than in the control group $(P<0.001)$; however, TLR4 expression was not significantly different between the two groups $(P=0.656)$. Conclusion: TLRs are thought to play a role in the etiopathogenesis of NP. In addition, the authors consider that a possible treatment for NP could be a TLR-specific treatment. Thus, in the future it will be essential to determine the extent to which TLRs function in NP formation and to apply this knowledge to design a specific therapeutic regimen for the enhanced treatment of NP.
\end{abstract}

\section{Keywords}

Nasal Polyposis, Toll-Like Receptor, Gene Expression, Etiopathogenesis

\footnotetext{
${ }^{*}$ Corresponding author.
}

How to cite this paper: Yurttas, V., Apuhan, T., Simsek, T., Ocak, Z. and Gok, U. (2016) Toll-Like Receptor Gene Expression in Nasal Polyp. International Journal of Otolaryngology and Head \& Neck Surgery, 5, 90-95. 


\section{Introduction}

Nasal polyps are benign lesions arising from the mucosa of the nasal sinuses or nasal cavity. Nasal polyposis (NP) occurring in the paranasal sinuses is characterized by basement membrane thickening, edema, fibrous tissue, vessel structures, and mucosal pouches, including glands [1]. NP is a chronic disease that typically occurs in adults and has a high recurrence rate despite treatment. Nasal polyps arising in the mucosal tissue of the medial meatus and anterior ethmoid cells, which protrude into the nasal passage, are benign lesions. Although the etiopathogenesis of nasal polyps is unknown, several hypotheses have been formulated, including allergies, infections, genetics, local immune responses, and anatomic variations, which can lead to osteomeatal complex obstruction resulting in tissue hypoxia. Specifically, genetics is thought to be a major contributor to the recurrence of NP. This is supported by patients who display repeated cases even after adequate surgery [2]. NP recurrence has also been linked to aspirin intolerance and cystic fibrosis, as well as other conditions in which an individual is immunocompromised [3]. Although there are several hypotheses regarding the etiopathogenesis of NP, it is considered a chronic inflammatory disease and is likely a complex process affected by multiple factors [3].

Toll-like receptors (TLRs) recognize features from bacterial, viral, and fungal pathogens [4]. To date, eleven different TLRs have been identified. In humans, TLRs play a major role in innate and adaptive immunity [5]-[7]. TLRs are expressed in a wide variety of cells such as macrophages and dendritic cells; pathogens are recognized by TLRs when they enter the airway and encounter these innate immune system cells. Upon TLR activation in dendritic cells, a signaling cascade occurs resulting in the induction of cytokine expression as well as antigen presentation on the cell surface [8]. Dendritic cell cytokine production as well as antigen presentation on major histocompatibility complex molecules activates T cells, inducing Th1 or Th2 cell differentiation.

The aim of this study was to investigate the expression of TLRs and the correlation between TLR expression and mucosal changes in chronic sinusitis-related NP.

\section{Materials and Methods}

Patients from the Department of Otorhinolaryngology Head and Neck Surgery at Abant Izzet Baysal University (Bolu, Turkey) with nasal polyps arising from the medial meatus and protruding into the nasal passage were enrolled in this study as the experimental group between January 2013 and December 2013. The control group consisted of individuals undergoing surgery due to nasal obstruction caused by concha hypertrophy who were not diagnosed with chronic sinusitis-related NP. Exclusion criteria were the presence of an isolated anterochoanal polyp, unilateral nasal polyps, allergic fungal sinusitis (AFS), asthma, aspirin intolerance, or any other systemic diseases including Crohn's disease, primary immunodeficiency, malignancy, organ transplantation or previous nasal surgery.

There were 30 patients in the experimental group (individuals with NP) and 20 patients in the control group (individuals undergoing septoplasty and concha submucosal resection for nasal obstruction, but not diagnosed with chronic sinusitis or NP). In the experimental group, 18 of the 30 patients were male (60\%) and 12 were female (40\%). In the control group, 11 of the 20 patients were male (55\%) and 9 were female (45\%). All subjects were $>18$ years old but $<65$ years old, with a mean age of 46.14 years in the experimental group and 31.65 years in the control group. This study was approved by the Abant Izzet Baysal University Clinical Research Ethical Committee. Written informed consent was taken from the participants.

Sterile tissue samples were taken from the patients by endoscopic approach and were kept at $-80^{\circ} \mathrm{C}$. A piece of tissue sample was put into the eppendorf tube. Expression of TLR2 and TLR4 gene was investigated in the tissue samples. The samples were taken after the surgery; they were carried into the liquid nitrogen and were kept at $-80^{\circ} \mathrm{C}$ before study.

\section{Total RNA Isolation and CDNA Construction}

Tissue samples size was $1 * 1 \mathrm{~cm}$ and the appropriate amount of frozen tissue was $20 \mathrm{mg}$. RNA isolated from these tissues. High Pure RNA Tissue Kit (Roche Diagnostics. GmbH, Mannheim) was used for the isolation of RNA. The purified and quantity of total RNA is evaluated with spektrofotometric (Nano-Drop, ThermoScientific, ABD). Reverse transcription was performed using (Transcriptor High Fidelity cDNA Synthesis Kit (RocheDiagnostics. GmbH, Mannheim) from 200 ng of total RNA and the combination of anchored-oligo (dT) and random hexamer primers. Samples lacking reverse transcriptase were amplified to control for the presence of 
genomic DNA contamination.

\section{Real-Time PCR (TLR2 and TLR4)}

Commercially available Real Time ready assays for the two selected markers (TLR2 and TLR4) and for the 18 ribosomal RNA housekeeping gene were obtained lyophilized in 384 well PCR plates with forward and reverse primers $(60 \mu \mathrm{M})$ and fluorescently labeled hydrolysis probes $(20 \mu \mathrm{l})$ from Universal Probe Library (Roche Applied Science). Gene expression analysis was performed with real-time PCR reactions in a final volume of $15 \mu l$ $10 \mu \mathrm{l}$ using LightCycler ${ }^{\circledR} 480$ Probes Master, $1 \mu \mathrm{l}$ Real Time ready Assay and $4 \mu \mathrm{l}$ diluted sample (5 ng cDNA/ well). The following thermal cycling conditions were applied on the Light Cycler 480 Instrument: enzyme activation and denaturation at $95^{\circ} \mathrm{C}$ for $10 \mathrm{~min}, 45$ cycles of amplification: $95^{\circ} \mathrm{C}$ for $10 \mathrm{~s}, 60^{\circ} \mathrm{C}$ for $30 \mathrm{~s}$ and signal detection at $72^{\circ} \mathrm{C}$ for $1 \mathrm{~s}$ with detection and cooling at $40^{\circ} \mathrm{C}$ for $30 \mathrm{~s}$. Statistical evaluation of RT-PCR results according to evaluate between referans and target ratio.

\section{Statistical Analysis}

Statistical analyses were performed with the software package SPSS 21.0. The following tests were used for specific analysis: Frekans analysis was used to assess demographic information, a nonparametric chi-square test was performed for statistical comparisons, a Spearman correlation test was used to make correlations, and the Kruskal-Wallis test was used to analyze comparisons among groups. For all statistical tests, $P=0.05$ was considered significant.

\section{Results}

Prior to this study, 10 patients from the study group (33.3\%) had undergone at least one operation for NP, 27 patients from the experimental group (90\%) had used topical medical treatment prior to surgery, and 9 of the patients (30\%) had used oral corticosteroids prior to surgery.

In total, eleven patients from the experimental group (36.7\%) and five patients from the control group (25\%) had an allergy; further, six patients in the experimental group (20\%) had bronchial asthma, whereas only one patient in the control group (5\%) had asthma. Within the experimental group, two patients (6.7\%) had aspirin intolerance compared to zero patients in the control group. TLR2 and TLR4 expression was measured in both groups and then analyzed using Student's $t$-test. In the experimental group, the level of TLR2 expression was significantly higher than in the control group $(P<0.001)$; however, TLR4 expression was not significantly different between the two groups $(P=0.656)$ (Figure 1, Figure 2).

TLR2

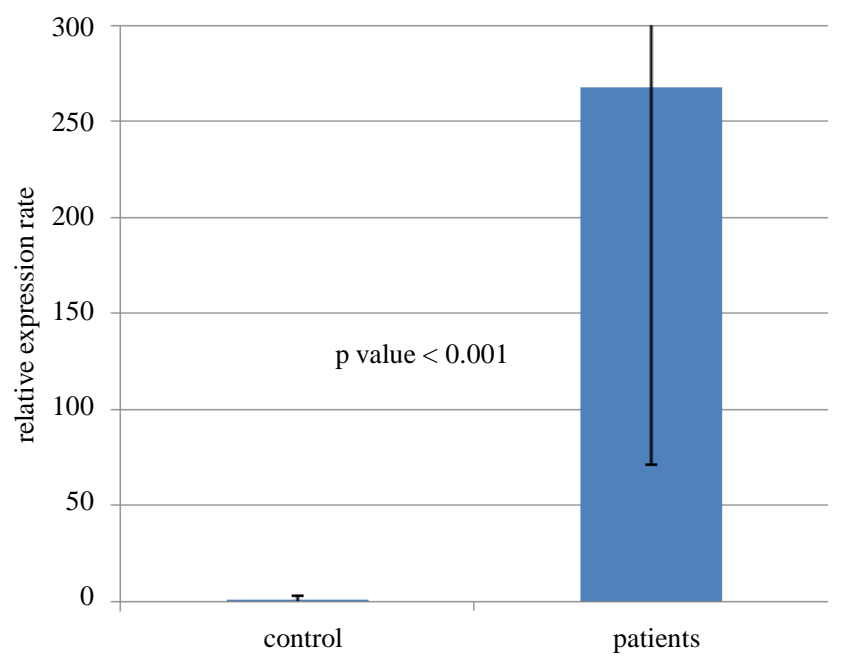

Figure 1. Between control group and study group association about TLR2 gene expression. 
TLR4

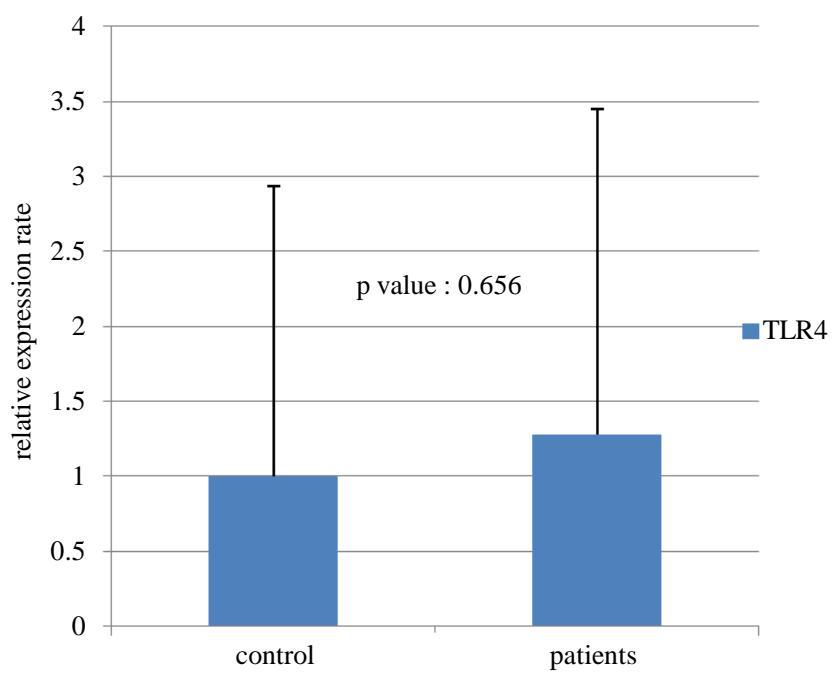

Figure 2. Between control group and study group association about TLR4 gene expression.

\section{Discussion}

Nasal Polyposis (NP) can be diagnosed and treated; however, the etiopathogenesis remains unknown. There are several hypotheses regarding the etiopathogenesis of NP [9]. Suggested related factors included environmental factors, allergies, genetic background, Staphylococcus superantigens, microbial infections, disorders associated with Bernoulli's phenomenon, primary ciliary dyskinesia, Samter's Triad (Fernand Widal syndrome), ChurgStrauss syndrome, cystic fibrosis, and Young's syndrome [10].

Besides, cytokines, growth factors, adhesion molecules, and other factors (e.g., interleukins, chemokines, matrix metalloproteinases, inflammatory cell infiltrates, and nitric oxide) were found to be associated with NP.

Airborne microorganisms are recognized by pattern recognition receptors (PRRs), which are components of the innate immune system in mammals [11]. TLR family proteins are a prime example of PRRs [11]. TLR plays an essential role in recognizing distinct microbial components and triggering a signaling cascade that directly activates other immune cells. TLRs can recognize a wide range of pathogen-associated molecular patterns derived from bacteria, fungi, and viruses.

Patterns of TLR expression have been studied in many different tissues and cell types. TLR2 and TLR4 are expressed in nasal epithelial cells of the upper respiratory tract. The expression of these two genes has been observed to be significantly higher in patients with chronic rhinosinusitis (CRS) compared to those without an infection. Another study demonstrated the mRNA and protein expression of TLRs 2, 3, and 4 in the nasal mucosa of patients with intermittent allergic rhinitis [12]-[14]. Furthermore, an increase in the protein expression of all three of these receptors was observed in the nasal mucosa of individuals following an allergen challenge [15].

In previous studies, it was noted that TLR mRNA was present in the sinonasal mucosa of CRS patients [16] [17]. Lane et al. [17] reported that patients with CRS expressed significantly higher levels of TLR2 mRNA than healthy individuals. Zhao et al. [18] investigated the expression of TLRs 1 - 10 in CRS patients by microarray analysis and detected the upregulation of TLR9 in nasal polyp tissue. In contrast, Zhang et al. [19] revealed that CRS patients with nasal polyps (CRSwNP) expressed significantly more TLR2, TLR4, and TLR7 within nasal polyp tissue compared with nasal mucosal tissues from control subjects and CRS patients without nasal polyps (CRSsNP). They also detected an increase in the expression of interleukin (IL)-4, a cytokine whose expression occurs after TLR activation and the subsequent signaling cascade [19]. These results suggest that CRSwNP exhibit an excessively activated TLR-mediated signaling pathway, which might contribute to the observed inflammation and formation of nasal polyps in CRSwNP. In a study by Hamilos et al. [20], 12\% of CRSsNP had a deficiency in antibody production in response to vaccination or low immunoglobulins, indicating that there may be a humoral immune deficiency in CRSsNP. Collectively, these studies illustrate that CRSsNP are likely to 
have an innate and/or humoral immunodeficiency. A deficiency in the innate immune system of the nasal mucosa could result in microbial colonization and subsequent chronic inflammation of the airways, which might explain the latency of NP development associated with CRSsNP. The results of the present study also demonstrate a significant increase in the expression of TLR2, TLR4, and TLR7 in nasal polyp tissues from CRSwNP compared to that in nasal mucosal tissues from control subjects and CRSsNP. Previous experimental and clinical studies have suggested that the overexpression of certain TLRs can lead to a more robust immune response to commensal bacteria [17] [18] [21]. In addition, TLR9 expression has been observed to be upregulated in nasal polyps [18]. Similarly, Lane et al. [17] reported that CRS patients had increased levels of TLR2 expression when compared with healthy individuals. Another study suggested that nasal polyps are more sensitive to airborne microorganisms, and, as a result, that the TLR-mediated signaling pathway in nasal polyps is more readily activated than that in normal nasal mucosa. This observation is supported by the significantly increased expression of TLR2, TLR4, TLR7, and IL-4, which are markers of excessive inflammation [19]. These studies suggest that there is likely an increase in microorganisms colonizing nasal polyps, which might result in the increase in TLR expression seen in CRSwNP. In the present study, the increased expression of TLRs in the nasal mucosa of CRSwNP may be related to some of the above mentioned hypotheses. Future studies should explore these hypotheses in greater detail. In this study, it was observed that TLR2 expression was significantly higher in patients with NP compared to control subjects $(P<0.005)$; however, no difference was seen in TLR4 gene expression between these samples.

To date, the treatment of inflammatory diseases has relied solely on broad spectrum inhibitors of inflammatory mediators. These therapies are aimed primarily at treating symptoms, rather than providing a cure. Furthermore, these treatments have to be applied over a long period of time, which can result in negative side effects (e.g., increased infections) as the immune system is temporarily impaired on a large scale. Targeting certain TLRs might provide a more specific target for the treatment of inflammatory diseases. A treatment with increased specificity would reduce nonspecific inhibition of the immune system and reduce side effects; moreover, it may result in curing the disease. To further characterize the distinct functions of each TLR within specific tissues, the use of specific blocking antibodies as well as emerging technologies such as siRNA should be utilized. Additional studies are necessary to determine the role of TLR signaling in specific tissues [22].

\section{Conclusion}

TLRs are thought to play a role in the etiopathogenesis of NP. In addition, the author considers that a possible treatment for NP could be a TLR-specific treatment. Thus, in the future it will be essential to determine the extent to which TLRs function in NP formation and to apply this knowledge to design a specific therapeutic regimen for the enhanced treatment of NP.

\section{Financial Disclosure}

This study is founded by Abant İzzet Baysal University, Bolu, Turkey, Project No: 2014.08.16.734

\section{Conflict of Interest}

There are no conflicts of interest

\section{References}

[1] Bernstein, J.M., Gorfien, J., Noble, B. and Yankaskas, J. (1997) Nasal Polyposis: Immunhistochemistry and Bioelectric Findings (a Hypothesis for the Development of the Nasal Polyps). Journal of Allergy and Clinical Immunology, 2, 165175. http://dx.doi.org/10.1016/S0091-6749(97)70091-5

[2] Bernstein, J.M., Gorfien, J. and Noble, B. (1995) Role of Allergy in Nasal Polyposis: A Review. Otolaryngology-Head \& Neck Surgery, 113, 724-732. http://dx.doi.org/10.1016/S0194-5998(95)70012-9

[3] Kirtsreesakul, V. (2005) Update on Nasal Polyps: Etiopathogenesis. Journal of the Medical Association of Thailand, 88, 1966-1972.

[4] Liu, G. and Zhao, Y. (2007) Toll-Like Receptors and Immune Regulation: Their Direct and Indirect Modulation on Regulatory CD4+ CD25+ T Cells. Immunology, 122, 149-156. http://dx.doi.org/10.1111/j.1365-2567.2007.02651.x 
[5] Anderson, K.V. (2000) Toll Signaling Pathways in the Innate Immune Response. Current Opinion in Immunology, 12, 13-19. http://dx.doi.org/10.1016/S0952-7915(99)00045-X

[6] Medzhitov, R. (2001) Toll-Like Receptors and Innate Immunity. Nature Reviews Immunology, 1, 135-145. http://dx.doi.org/10.1038/35100529

[7] Kapsenberg, M.L. (2003) Dendritic-Cell Control of Pathogen-Driven T-Cell Polarization. Nature Reviews Immunology, 3, 984-993. http://dx.doi.org/10.1038/nri1246

[8] Arancibıa, S.A., Beltrán, C.J., Aguırre, I.M., et al. (2007) Toll-Like Receptors Are Key Participants in Innate Immune Responses. Biological Research, 40, 97-112. http://dx.doi.org/10.4067/S0716-97602007000200001

[9] Perez-novo, A.C., Kowalski, M.L., Kuna, P. and Ptasinska, A. (2004) Aspirin Sensitivity and IgE Antibodies to Staphylococcus Aureus Enterotoxins in Nasal Polyposis: Studies on the Relationship. International Archives of Allergy and Immunology, 133, 255-260. http://dx.doi.org/10.1159/000076832

[10] Muñoz del Castillo, F., Jurado-Ramos, A., Fernández-Conde, B.L., et al. (2009) Allergenic Profile of Nasal Polyposis. Journal of Investigational Allergology and Clinical Immunology, 19, 110-116.

[11] Bachert, C., Gevaert, P., Holtappels, G. and van Cauwenberge, P. (2002) Mediators in Nasal Polyposis. Current Allergy and Asthma Reports, 2, 481-487. http://dx.doi.org/10.1007/s11882-002-0088-9

[12] Cheng, W., Zheng, C., Tian, J. and Shi, G. (2007) T Helper Cell Population and Eosinophilia in Nasal Polyps. Journal of Investigational Allergology and Clinical Immunology, 17, 297-301.

[13] Psaltis, A.J., Weitzel, E.K., Ha, K.R. and Wormald, P.J. (2008) The Effect of Bacterial Biofilms on Post-Sinus Surgical Outcomes. American Journal of Rhinology, 22, 1-6. http://dx.doi.org/10.2500/ajr.2008.22.3119

[14] Prince, A.A., Steiger, J.D., Khalid, A.N., et al. (2008) Prevalence of Biofilm-Forming Bacteria in Chronic Rhinosinusitis. American Journal of Rhinology, 22, 239-245. http://dx.doi.org/10.2500/ajr.2008.22.3180

[15] Jackson, D.W., Suzuki, K., Oakford, L., et al. (2002) Biofilm Formation and Dispersal under the Influence of the Global Regulator CsrA of Escherichia coli. Journal of Bacteriology, 184, 290-301. http://dx.doi.org/10.1128/JB.184.1.290-301.2002

[16] Kawai, T. and Akira, S. (2010) The Role of Pattern-Recognition Receptors in Innate Immunity: Update on Toll-Like Receptors. Nature Immunology, 11, 373-384. http://dx.doi.org/10.1038/ni.1863

[17] Dong, Z., Yang, Z. and Wang, Z. (2005) Expression of TLR2 and TLR4 Messenger RNA in the Epithelial Cells of the Nasal Airway. American Journal of Rhinology, 19, 236-239.

[18] Sha, Q., Truong-Tran, A.Q., Plitt, J.R., Beck, L.A. and Schleimer, R.P. (2004) Activation of Airway Epithelial Cells by Toll-Like Receptor Agonists. American Journal of Respiratory Cell and Molecular Biology, 31, 358-364. http://dx.doi.org/10.1165/rcmb.2003-03880C

[19] Guillot, L., Le Goffic, R., Bloch, S., et al. (2005) Involvement of Toll-Like Receptor 3 in the Immune Response of Lung Epithelial Cells to Double-Stranded RNA and Influenza A Virus. Journal of Biological Chemistry, 280, 55715580. http://dx.doi.org/10.1074/jbc.M410592200

[20] Vandermeer, J., Sha, Q., Lane, A.P. and Schleimer, R.P. (2004) Innate Immunity of the Sinonasal Cavity: Expression of Messenger RNA for Complement Cascade Components and Toll-Like Receptors. Archives of OtolaryngologyHead and Neck Surgery, 130, 1374-1380. http://dx.doi.org/10.1001/archotol.130.12.1374

[21] Lane, A.P., Truong-Tran, Q.A., Myers, A., Bickel, C. and Schleimer, R.P. (2006) Serum Amyloid A, Properdin, Complement 3, and Toll-Like Receptors Are Expressed Locally in Human Sinonasal Tissue. American Journal of Rhinology, 20, 117-123.

[22] Ritter, M., Mennerich, D., Weith, A. and Seither, P. (2005) Characterization of Toll-Like Receptors in Primary Lung Epithelial Cells: Strong Impact of the TLR3 Ligand Poly(I:C) on the Regulation of Tolllike Receptors, Adaptor Proteins and Inflammatory Response. Journal of Inflammation (London), 29, 16. http://dx.doi.org/10.1186/1476-9255-2-16 